\title{
Merging pathology with biomechanics using CHIMERA (Closed-Head Impact Model of Engineered Rotational Acceleration): a novel, surgery-free model of traumatic brain injury
}

Dhananjay R Namjoshi ${ }^{1,2+}$, Wai Hang Cheng ${ }^{1+}$, Kurt A Mclnnes ${ }^{3,4}$, Kris M Martens ${ }^{1}$, Michael Carr ${ }^{1}$, Anna Wilkinson ${ }^{1}$, Jianjia Fan', Jerome Robert ${ }^{1}$, Arooj Hayat ${ }^{1}$, Peter A Cripton ${ }^{3,4}$ and Cheryl L Wellington ${ }^{1,4,5^{*}}$

\begin{abstract}
Background: Traumatic brain injury (TBI) is a major health care concern that currently lacks any effective treatment. Despite promising outcomes from many preclinical studies, clinical evaluations have failed to identify effective pharmacological therapies, suggesting that the translational potential of preclinical models may require improvement. Rodents continue to be the most widely used species for preclinical TBI research. As most human TBIs result from impact to an intact skull, closed head injury (CHI) models are highly relevant, however, traditional CHI models suffer from extensive experimental variability that may be due to poor control over biomechanical inputs. Here we describe a novel CHI model called CHIMERA (Closed-Head Impact Model of Engineered Rotational Acceleration) that fully integrates biomechanical, behavioral, and neuropathological analyses. CHIMERA is distinct from existing neurotrauma model systems in that it uses a completely non-surgical procedure to precisely deliver impacts of prescribed dynamic characteristics to a closed skull while enabling kinematic analysis of unconstrained head movement. In this study, we characterized head kinematics as well as functional, neuropathological, and biochemical outcomes up to $14 \mathrm{~d}$ following repeated TBI (rTBI) in adult C57BL/6 mice using CHIMERA.
\end{abstract}

Results: Head kinematic analysis showed excellent repeatability over two closed head impacts separated at $24 \mathrm{~h}$. Injured mice showed significantly prolonged loss of righting reflex and displayed neurological, motor, and cognitive deficits along with anxiety-like behavior. Repeated TBI led to diffuse axonal injury with extensive microgliosis in white matter from 2-14d post-rTBI. Injured mouse brains also showed significantly increased levels of TNF- $a$ and IL-1 $\beta$ and increased endogenous tau phosphorylation.

Conclusions: Repeated TBI using CHIMERA mimics many of the functional and pathological characteristics of human TBI with a reliable biomechanical response of the head. This makes CHIMERA well suited to investigate the pathophysiology of TBI and for drug development programs.

Keywords: Traumatic brain injury, Animal model of traumatic brain injury, Animal model of closed head injury, Diffuse axonal injury, Microglia activation, Neuroinflammation, Tau hyperphosphorylation, Head kinematics, Head injury biomechanics, Impact-acceleration traumatic brain injury model, Surgery-free animal model of traumatic brain injury, Traumatic brain injury biomechanics

\footnotetext{
* Correspondence: wcheryl@mail.ubc.ca

${ }^{\dagger}$ Equal contributors

'Department of Pathology and Laboratory Medicine, The University of British

Columbia, Vancouver, BC, Canada

${ }^{4}$ International Collaboration on Repair Discoveries, The University of British

Columbia, Vancouver, BC, Canada

Full list of author information is available at the end of the article
} 


\section{Background}

Traumatic brain injury (TBI) is a leading worldwide cause of death and disability for persons under 45 years of age with a cost to society of over 17 billion USD per year. In the United States, the overall incidence of TBI is estimated to be 538 per 100,000 persons, which represents at least 1.7 million new cases per year since 2003 [1-3]. TBI incidence is reportedly lower in Europe (235 per 100,000) and Australia (322 per 100,000) [4,5] although recent epidemiological data suggests far greater incidence (749 per 100,000) [6]. Mild TBI (mTBI), which includes concussion, comprises over $75 \%$ of all TBIs [3]. As mTBI is increasingly recognized as an injury for which medical attention should be sought, the reported incidence of $\mathrm{mTBI}$ is rising.

Falls are the most prevalent cause of TBI, and motor vehicle accidents and impacts against objects are also common causes $[2,4,7]$. TBI resulting from high-contact sports such as boxing, American football, ice hockey, soccer, and rugby account for almost $21 \%$ of all head injuries among children and adolescents, particularly for mTBI [8]. In these situations, the skull experiences an impact resulting in brain deformation and resulting injury that most often occurs without skull fracture. TBI is also considered a "signature injury" in modern warfare, as approximately $20 \%$ of veterans from the Iraq or Afghanistan wars are reported to have experienced a TBI, $80 \%$ of which involve both blunt impact and overpressure mechanisms [9-12]. Furthermore, the growing awareness that mTBI may have long-lasting and severe consequences [13-16] highlights the urgency to understand much more about the acute and long-term consequences of brain injury.

Rapid acceleration and rotation during impact TBI lead to vigorous movement and deformation of brain tissue within the skull that can result in contusions as the brain contacts the interior of the bony skull. These inertial and contact forces directly affect neurons, blood vessels, and glia, producing a primary injury that initiates secondary processes within hours to weeks after the initial injury [17-22]. These secondary changes lead to a plethora of events including edema, raised intracranial pressure, impaired cerebral blood flow, increased blood-brain barrier permeability, inflammation, axonal injury, calcium influx, elevated oxidative stress, free radical-mediated damage, excitatory neurotransmitter release, and cell death [17-22]. Although few treatment options are available for the primary injury, secondary injury pathways are potentially modifiable [23]. An increasingly wide variety of experimental animal models are therefore being developed to characterize secondary injury processes and for the evaluation of candidate therapeutic approaches.

No single animal model can replicate the entire spectrum of human TBI pathophysiology; therefore, several large and small animal models have been developed to mimic particular aspects. Popular rodent models include open-head injury models such us fluid percussion (FP) and controlled cortical impact (CCI) systems, and closed-head injury (CHI) models that use either gravity or mechanical methods to impact the intact skull (reviewed in [24]). Although FP and CCI models employ highly reproducible mechanical inputs and can mimic many pathological features of human TBI, the prominent tissue destruction and lack of head movement in these models decreases their resemblance to the majority of human injuries that occur due to impact and/or acceleration on an intact skull. In contrast, closed-head injury (CHI) models employ methods that do not generally cause overt brain tissue loss and can also allow rapid behavioral assessment of injury severity. As such, $\mathrm{CHI}$ models are considered by some to better mimic the majority of human TBI cases. However, a major limitation of most current $\mathrm{CHI}$ animal models is that the input parameters used to induce injury (e.g., mechanical loading, method of mechanical input, and response of the animal's head to mechanical loading) are often poorly controlled, which can contribute to the considerable experimental variation across cognitive, histological, and biochemical outcome measures (reviewed in [24]).

Here we report a novel neurotrauma model called CHIMERA (Closed-Head Impact Model of Engineered Rotational Acceleration). CHIMERA was developed to address the absence of a simple and reliable model of rodent $\mathrm{CHI}$ that is representative of the majority of human TBI cases. CHIMERA is distinct from existing neurotrauma model systems in that it fully integrates biomechanical, behavioral, and neuropathological analyses after delivering impacts of defined energy to a closed skull with unconstrained head motion after impact. Here we show that repeated TBI (rTBI) in mice using CHIMERA reliably induces motor deficits, anxiety-like behavior, memory impairment, and leads to persistent diffuse axonal injury (DAI) with extensive white matter inflammation and increased phosphorylation of endogenous tau.

\section{Results}

\section{Head kinematics during CHIMERA rTBI}

Analysis of high-speed videography (5,000 fps) was used to assess the biomechanical responses of the head in a group of 8 mice during CHIMERA rTBI at an impact energy of $0.5 \mathrm{~J}$ (Figure 1; peak kinematic parameters depicted in Figure 1H). Trajectories of the mouse head in the sagittal plane during peak acceleration following two impacts spaced at $24 \mathrm{~h}$ are depicted in Figure 1A. Following vertical impact, the head followed a looped trajectory in the sagittal plane (Additional file 1: Figure S1, and Additional file 2: Movie S4). The average head trajectories following two repetitive TBIs in 8 mice were highly consistent (Figure 1A). The head traveled a peak 


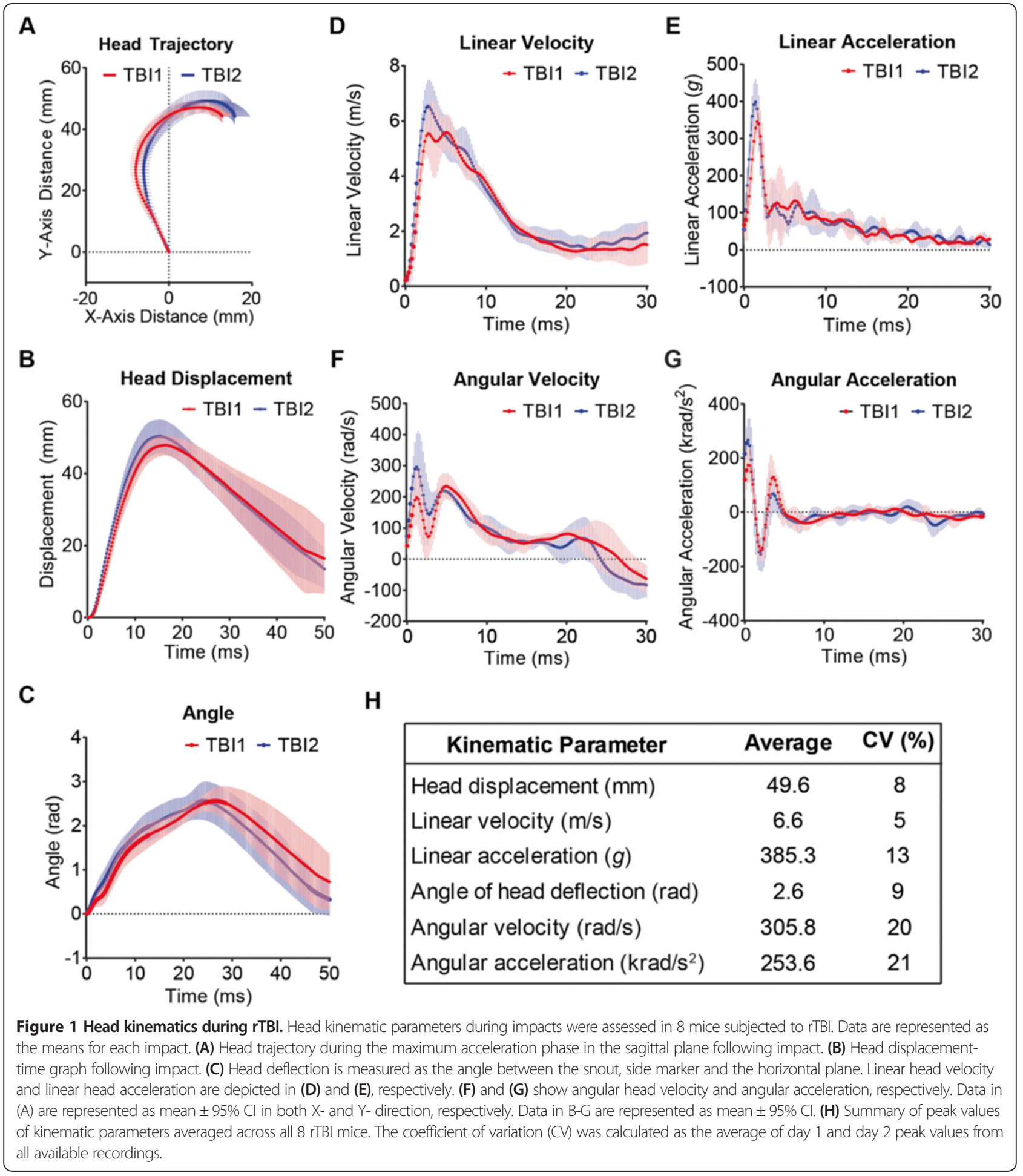

linear displacement of $49.6 \pm 3.5 \mathrm{~mm}$ (mean $\pm \mathrm{SD}$, same below) in $15.7 \pm 2.4 \mathrm{~ms}$ (Figure 1B) and exhibited a peak angular deflection of $2.6 \pm 0.28 \mathrm{rad}$ in $24.8 \pm$ $3.1 \mathrm{~ms}$ (Figure 1C). Peak linear velocity was $6.6 \pm$ $0.8 \mathrm{~m} / \mathrm{s}$ at $3.4 \pm 1.0 \mathrm{~ms}$ (Figure 1D), and peak angular velocity was $305.8 \pm 73.7 \mathrm{rad} / \mathrm{s}$ at $2.8 \pm 1.9 \mathrm{~ms}$ following initial impactor contact (Figure 1F). The head experienced large linear and angular accelerations following impact, achieving peak linear acceleration of $385.3 \pm 52 \mathrm{~g}$ at $1.5 \pm 0.3 \mathrm{~ms}$ (Figure 1E), whereas the peak angular 
acceleration of $253.6 \pm 69.0 \mathrm{krad} / \mathrm{s}^{2}$ was observed at $0.8 \pm$ $1.1 \mathrm{~ms}$ (Figure 1G). As the head was stationary before impact, the change in head velocity $(\Delta \mathrm{V})$ equals peak head velocity and was found to be $6.6 \mathrm{~m} / \mathrm{s}$. The energy transferred from the piston to the head was $0.07 \mathrm{~J}$.

Using the equal stress/equal velocity approach [25-27] to scale our murine kinematic data to human-equivalent values, $\Delta \mathrm{V}$ was found to be comparable to National Football League (NFL) values and higher than Olympic boxing values, whereas scaled linear and angular velocity and acceleration parameters were lower than NFL values but comparable to Olympic boxing values (Additional file 3: Table S5).

\section{CHIMERA rTBI induces behavioral deficits}

Loss of righting reflex (LRR) in animals after TBI is considered analogous to loss of consciousness in humans after TBI and can be considered as a behavioral indicator of injury severity [28]. Mice subjected to CHIMERA rTBI showed significantly increased LRR duration compared to sham animals (Figure 2A; TBI effect: $F(1,65)=$ 59.61, $p<0.001)$. LRR duration was consistent between the first and second impacts (Figure 2A). We further assessed injury severity using the Neurological Severity Score (NSS), which is a composite of ten tasks that assess motor reflexes, alertness, and physiological behavior [29] (Additional file 4: Table S6). The NSS of injured

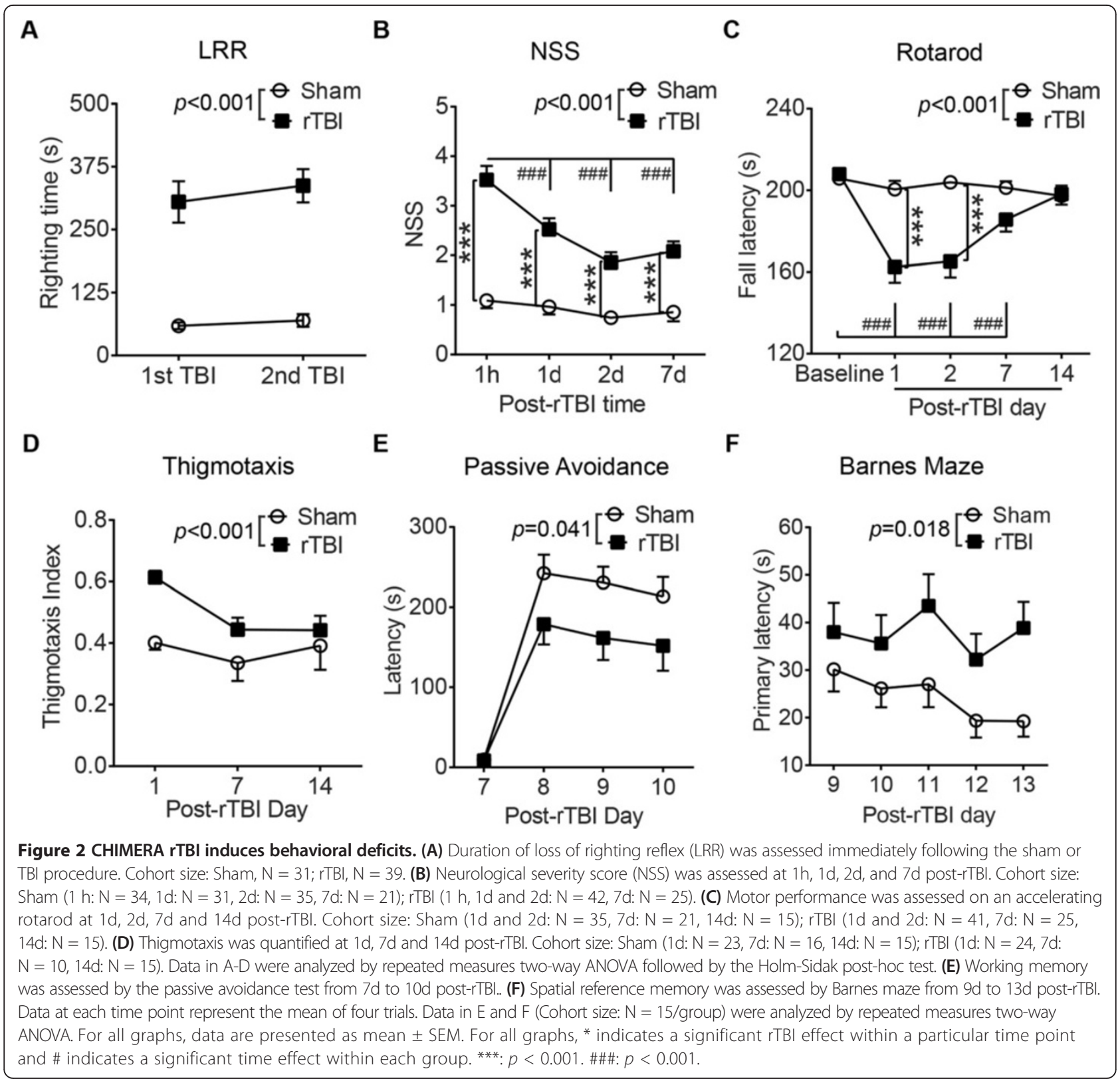


animals was significantly higher than sham mice from $1 \mathrm{~h}$ to $7 \mathrm{~d}$ post-procedure (Figure 2B, TBI effect: $F(1,191)=44.12, p<0.001)$. In injured mice, the NSS score showed maximum deficits at $1 \mathrm{~h}$ post-procedure $(p<0.001)$ followed by steady spontaneous improvement over $1-7 d$, albeit remaining significantly higher than sham animals at each post-rTBI time point (Figure 2B, $p<0.001)$. Similarly, rTBI significantly impaired motor performance from $1-7 \mathrm{~d}$ post-injury as indicated by reduced fall latencies on an accelerating rotarod compared to sham controls (Figure 2C, TBI effect: $F(1,220)=$ 11.99, $p<0.001)$. Fall latencies showed both time effects $(F(4,220)=13.70, p<0.001)$ and TBI $\times$ Time interaction $(F(4,220)=11.22, p<0.001)$. Motor deficits in injured mice peaked at $1 \mathrm{~d}(p<0.001)$ and returned to baseline conditions by $14 \mathrm{~d}$ post-injury $(p=0.22)$, whereas sham mice did not show any motor deficit $(p>0.82)$. Injured mice showed anxiety-like behavior as indicated by significantly increased thigmotaxis in an open field test (Figure 2D, TBI effect: $F(1,53)=12.30, p<0.001)$. The thigmotactic behavior of both groups significantly declined over time in a similar trend (Figure 2D, Time effect: $F(2,53)=5.45, p=0.007$; TBI $\times$ Time interaction insignificant). Open field thigmotaxis was not affected by gross motor activity as no significant differences in total distance traveled or time immobile were observed between injured and sham-operated mice (Additional file 5: Figure S2). Repeated TBI also induced working memory impairment as indicated by decreased latencies to enter the darkened compartment on the passive avoidance task (Figure 2E, TBI effect: $F(1,28)=4.6, p=0.041$ ). For all mice, a main effect of Day indicated that mouse behavior changed over the training and testing sessions evaluated in this study $(F(3,84)=58.55, p<0.001)$. For the main effect of Day, pairwise comparisons indicated that mice entered the darkened compartment significantly faster on Day $7(p<0.001)$ than on Days 8-10 $(p>0.05)$, signifying that all mice remembered the shock to some degree (Figure 2E). Injured mice also showed spatial reference memory impairment as indicated by increased latencies to locate the escape hole on the Barnes maze (Figure 2F, TBI effect: $F(1,28)=6.27, p=0.018$ ). Under our experimental conditions, cognitive performance did not spontaneously resolve by the end of our testing period.

\section{CHIMERA rTBI induces widespread persistent diffuse axonal injury}

Silver staining was used to assess post-rTBI axonal damage at 2, 7, and 14d post-rTBI (Figures 3 and 4). rTBI brains revealed widespread axonal injury, as indicated by intense punctate and fiber-associated argyrophilic structures in several white matter tracts including the olfactory nerve layer of the olfactory bulb, corpus callosum, and optic tracts (Figure 3A and B, Figure 4). Axonal injury was observed at both coup (corpus callosum) and contrecoup (optic tract) regions, indicating a diffuse injury pattern. High-magnification of the affected areas at 100X revealed numerous axonal varicosities (Figure 3C, arrows), which is a characteristic histological feature of human axonal pathology after TBI [30]. Quantitative analysis revealed significant silver uptake in the injured olfactory nerve layer (TBI effect: $F(1,27)=16.89$, $p<0.0001)$, which was maximum at $2 \mathrm{~d}(p<0.001)$ and returned to sham levels over 7-14d (Figure 4A). On the other hand, rTBI induced persistent silver stain uptake in the corpus callosum (Figure 4B, TBI effect: $F(1,37)=$ 41.54, $p<0.0001$; Time effect insignificant) (Figure 4C). In the optic tract, silver uptake was most intense (Figures $3 \mathrm{~B}$ and $4 \mathrm{C}$ TBI effect: $F(1,36)=107.4$ ) and there was a significant time and injury interaction (TBI $x$ Time interaction: $F(2,36)=11.66)$, indicating persistent increase in axonal degeneration in contrecoup regions.

\section{CHIMERA rTBI induces widespread microgliosis and increases proinflammatory cytokine levels}

Using Iba-1 immunohistochemistry, we observed significantly increased microglial activation throughout several white matter tracts including the olfactory nerve layer, corpus callosum, optic tracts, and brachium of superior colliculus of injured brains compared to the sham controls as assessed using both fractal analysis and microglial density (Figures 5 and 6). Quantification of microglial morphology by fractal analysis revealed that microglia in sham animals displayed highly ramified and extensively branched processes that are characteristic of the resting state (Figure 5C, upper row, Figure 6A-D, open bars). By contrast, microglia in the corpus callosum, brachium of superior colliculus, and olfactory nerve layer of injured animals had predominantly hypertrophic to bushy morphology with primary branches only, whereas those in the optic tract showed amoeboid morphology characteristic of highly activated microglia (Figure 5C, lower row, Figure 6A-D, black bars). Quantitative analysis showed significant and persistent microglial activation in the injured olfactory nerve layer (TBI effect: $F(1,35)=13.64$, $p=0.0008$ ), optic tract (TBI effect: $F(1,37)=9.77$, $p=0.0034$ ), corpus callosum (TBI effect: $F(1,38)=29.51$, $p<0.0001$ ), and brachium of superior colliculus (TBI effect: $F(1,38)=24.5, p<0.0001$ ) as soon as 2d (Figure 6A, $\mathrm{B}, \mathrm{C}$ and $\mathrm{D})$.

In addition to changes in microglial morphology, we observed significant increases in the number of microglia in the same white matter regions including the olfactory nerve layer (Figure 6E, TBI effect: $F(1,16)=$ 21.53, $p=0.0003$ ), optic tract (Figure 6G, TBI effect: $F(1$, $16)=90.30, p=0.0001$ ), corpus callosum (Figure 6F, TBI effect: $F(1,19)=22.25, p=0.0002)$ and brachium of 


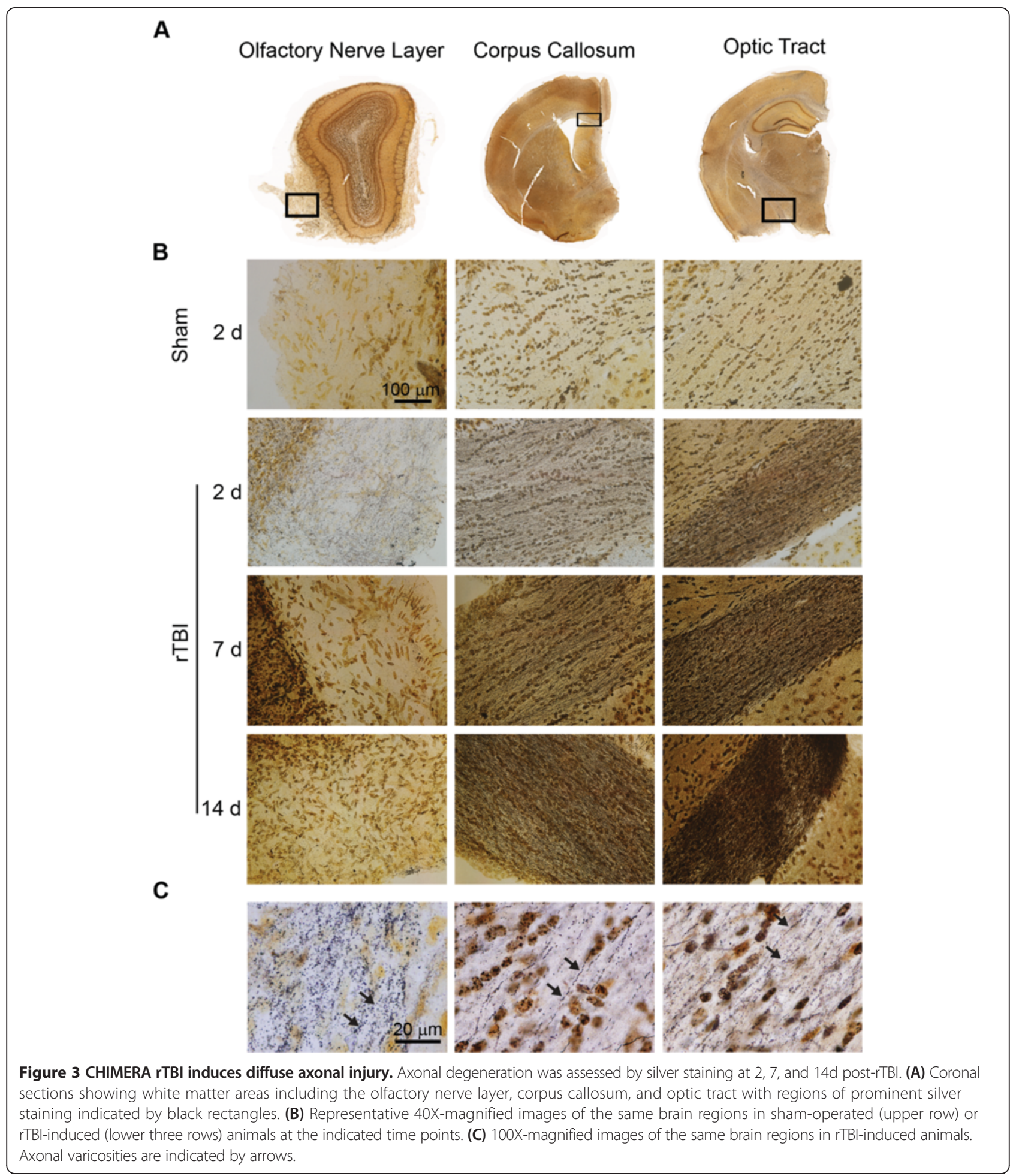

superior colliculus (Figure 6H, TBI effect: $F(1,18)=$ $34.85, p<0.0001)$, indicating that injury induced proliferation or recruitment of immune cells. In olfactory bulb (Time effect insignificant), corpus callosum (Time effect insignificant) and optic tract, microglia cell number was persistently increased from $2 \mathrm{~d}$ up to $14 \mathrm{~d}(p<0.05)$. In the brachium of superior colliculus, a delayed but persistent increase in the Iba- 1 positive cell number was observed from $7 \mathrm{~d}$ to $14 \mathrm{~d}(p<0.01)$.

In addition to the microglial response, we also measured protein levels of the proinflammatory cytokines TNF $\alpha$ and IL- $1 \beta$ in half brain homogenates. Protein 


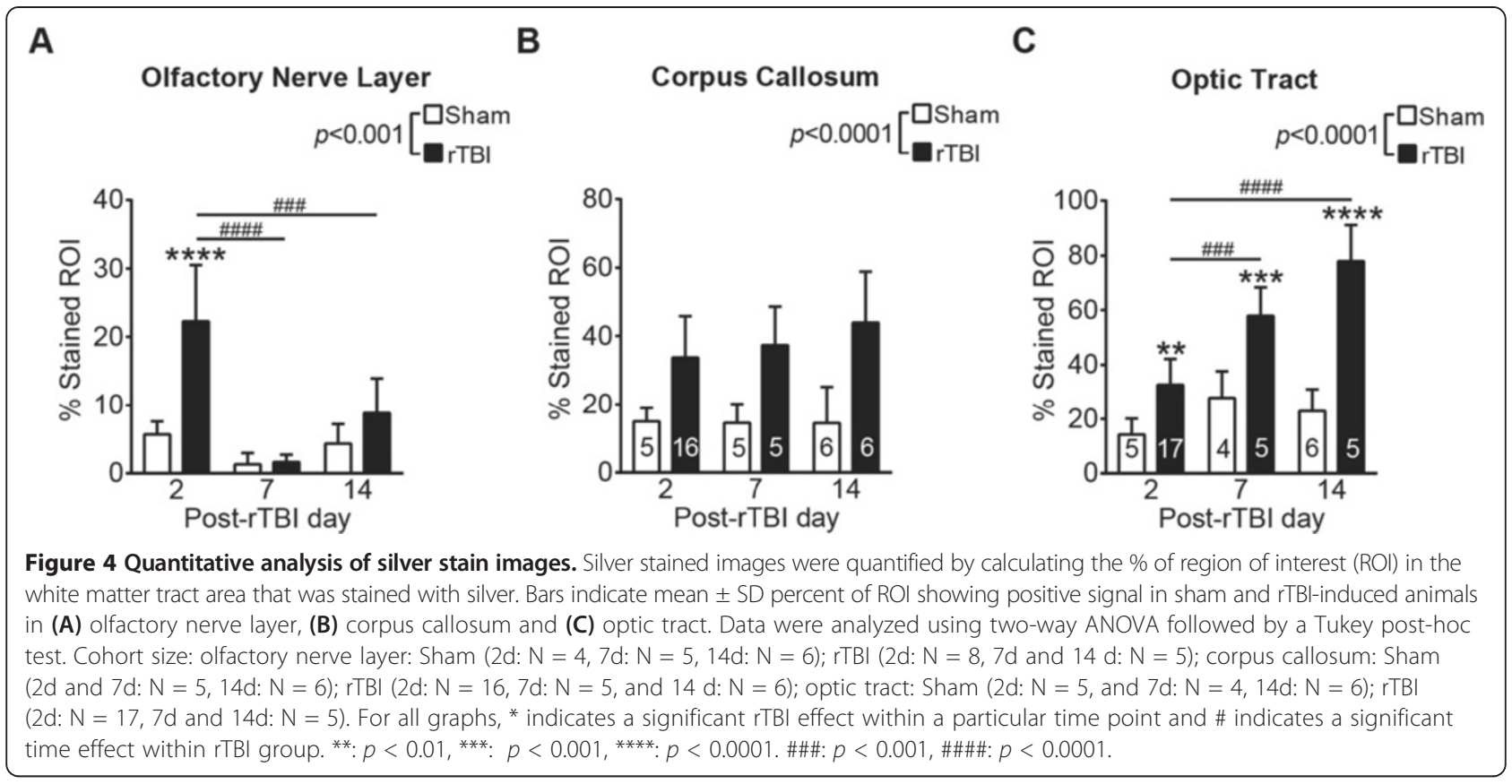

levels of TNF $\alpha$ (Figure 7A) and IL-1 $\beta$ (Figure 7B) were significantly higher at $2 \mathrm{~d}$ post-TBI compared to the respective sham levels $(p<0.01)$.

\section{CHIMERA rTBI increases endogenous tau phosphorylation}

We next assessed the phosphorylation levels of endogenous murine tau using three antibodies directed against different phosphorylation sites, namely CP13 (pSer202), RZ3 (pThr231), and PHF1 (pSer396 and pSer404). Total murine tau levels were determined by the antibody DA9. Simple Western analysis showed significantly increased phosphorylation of all the probed epitopes in rTBI brain lysates at $6 \mathrm{~h}, 12 \mathrm{~h}$, and $2 \mathrm{~d}$ compared to the respective sham brain lysates (Figure 8A-C and 8G-I, $p<0.01$ ). The change in tau phosphorylation reflected a significant increase in the ratio of phosphorylated tau:total tau, but not a change in total tau levels (Figure 8D-F and 8G-I, $p<0.01$ ).

\section{Discussion}

The major goal of this study was to develop a simple, reliable model of murine $\mathrm{CHI}$ that replicates fundamental aspects of human impact TBI through precise delivery of known biomechanical inputs. CHIMERA fulfills these criteria and offers several key advantages over existing rodent TBI models. CHIMERA is completely nonsurgical and requires only isoflurane anesthesia, therefore enabling immediate neurological severity assessments using LRR and NSS measures. Being nonsurgical, CHIMERA is ideal for studies investigating multiple impacts as well as the longterm consequences of impact TBI. These advantages overcome many limitations of surgically-induced TBI models, including longer exposure to multiple anesthetic agents, such as opioid analgesics (buprenorphine) and sedatives (xylazine) that can interfere with rapid neurological assessment. Surgical models are also low throughput, require extensive operator training, and have limited suitability for studies involving repetitive TBI or long-term TBI outcomes. By contrast, CHIMERA produces injury using a simple, reliable, and semi-automated procedure that requires $<10 \mathrm{~min}$ per animal to produce defined injury (Figure 9). As the biomechanical input parameters are highly adjustable across impact energy, velocity, and directional parameters, CHIMERA offers a wide dynamic range of precisely controllable inputs to reproduce specific conditions that occur in human impact TBI. Importantly, the kinematic analyses facilitated by CHIMERA enable head motion parameters to be integrated with behavioral and neuropathological outcomes, potentially enabling greatly improved translational relevance to human TBI. CHIMERA produces diffuse injury characterized by activation of inflammatory reactions, axonal damage, and tau phosphorylation, replicating many aspects of the neuropathology of human impact TBI without overt focal damage. Taken together, these attributes make CHIMERA a valuable new model to investigate the mechanisms of TBI and for use in preclinical drug discovery and development programs.

In this study, a $50 \mathrm{~g}$ piston was used to deliver an input impact with a kinetic input energy of $0.5 \mathrm{~J}$. Calibration curves show that the $50 \mathrm{~g}$ piston has an energy range of $0.01 \mathrm{~J}$ to $14.0 \mathrm{~J}$ (useful range for murine TBI is $0.1 \mathrm{~J}$ to $1 \mathrm{~J}$ ) in minimum steps of $0.01 \mathrm{~J}$, with highly reproducible performance (Figure 9D). Adjusting the piston mass and 


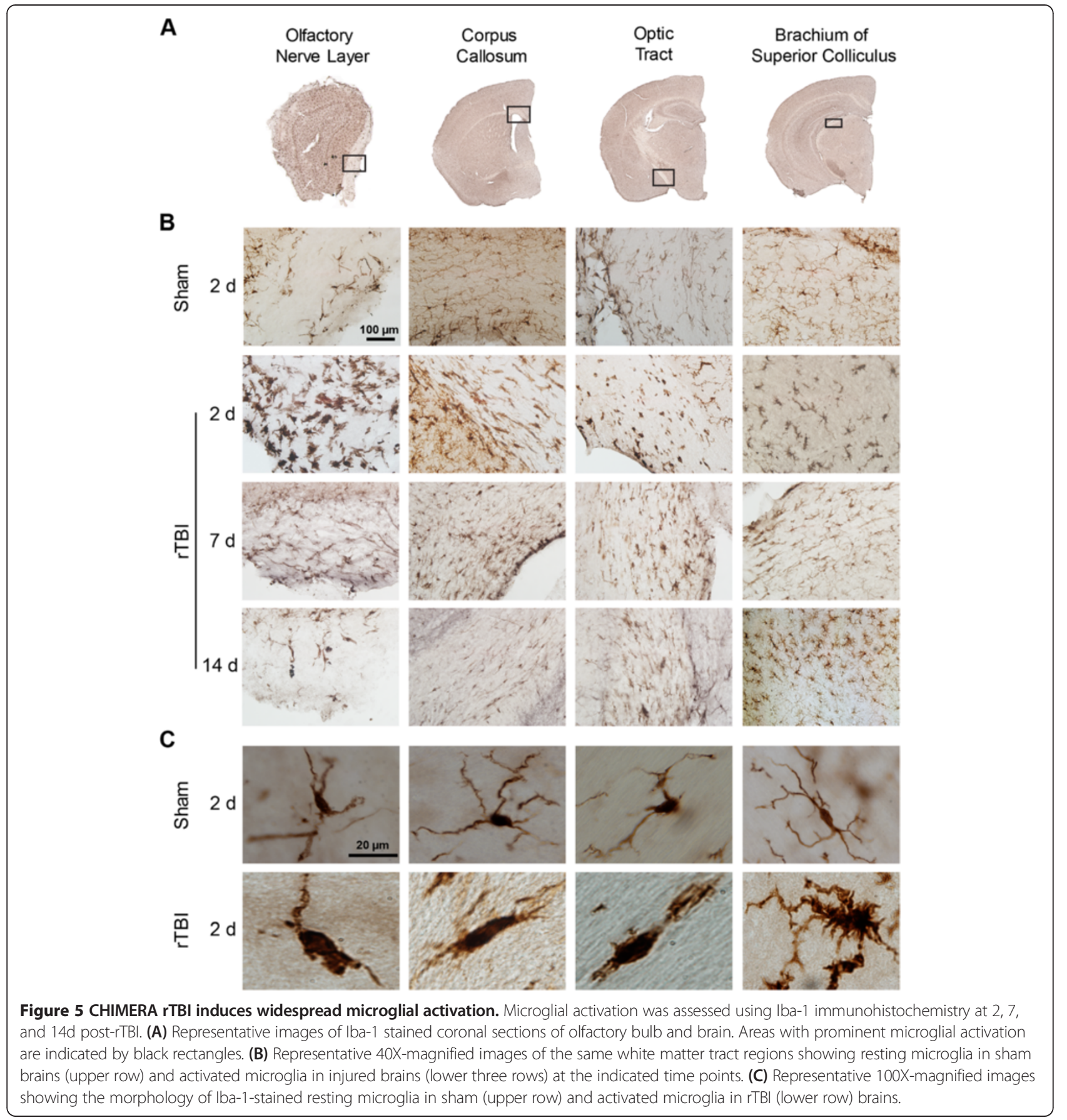

dimensions will allow other biomechanical parameters to be controlled, so that it may be possible to experimentally model the biomechanical conditions observed under different types of human impact TBI.

High-speed video integrated into CHIMERA enables measurement of mouse head kinematic parameters that can be scaled to humans. The most-commonly used method for scaling kinematic parameters between humans and animals is based on the equal stress/equal velocity approach [25-27]. Thus, velocity does not scale and is the same for human and animal data. We used a scaling factor $\lambda\left[\lambda=(\text { mass of human brain } / \text { mass of mouse brain })^{1 / 3}=\right.$ 13.8] to estimate the human head-equivalent kinematic parameters from our animal data. Although this scaling approach has been widely used in the study of impact biomechanics [25-27], and has been applied to a rat CHI model [25], it is important to be cautious in its extrapolation as the human and rodent brains differ in geometry, white:grey matter ratio, ventricular volume and position, and cortical folding. All of these factors 
A

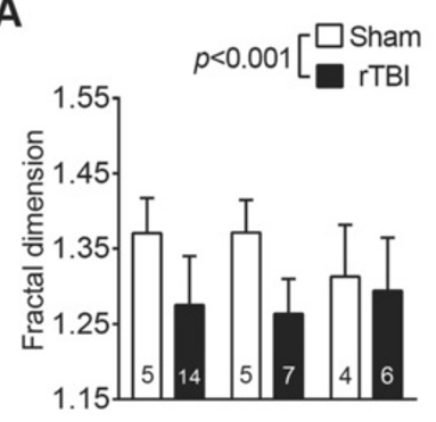

B
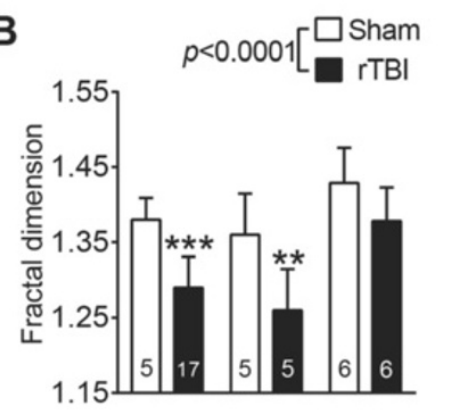

C
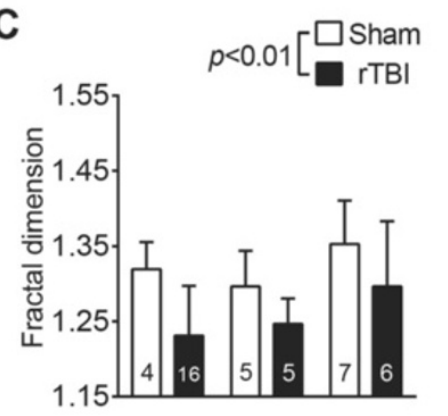

D

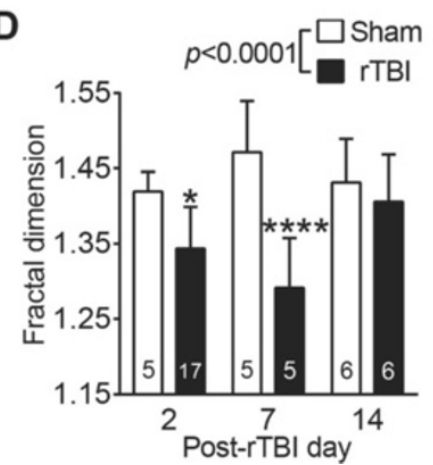

E

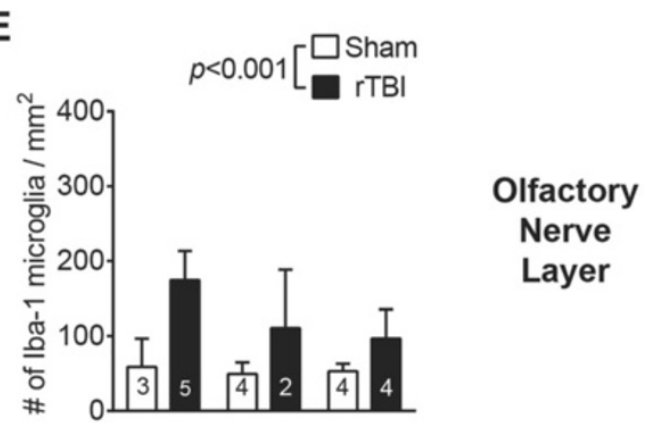

$\mathbf{F}$

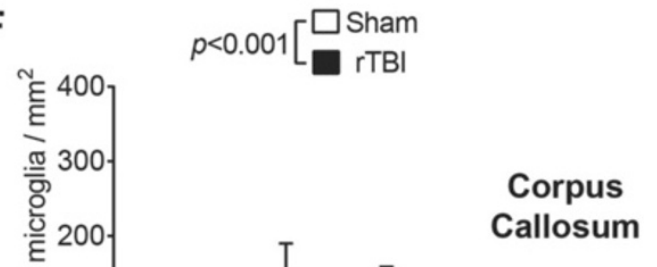

Optic

Tract

G

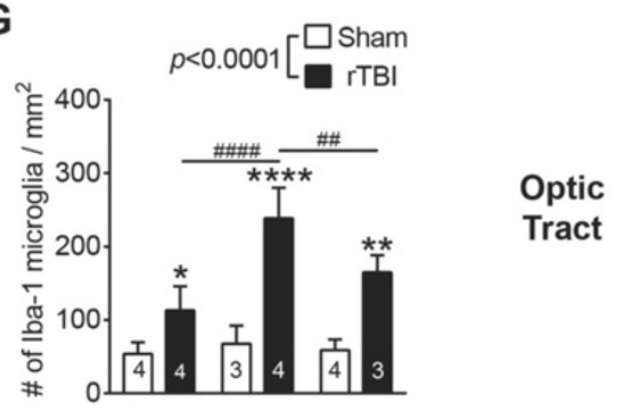

H

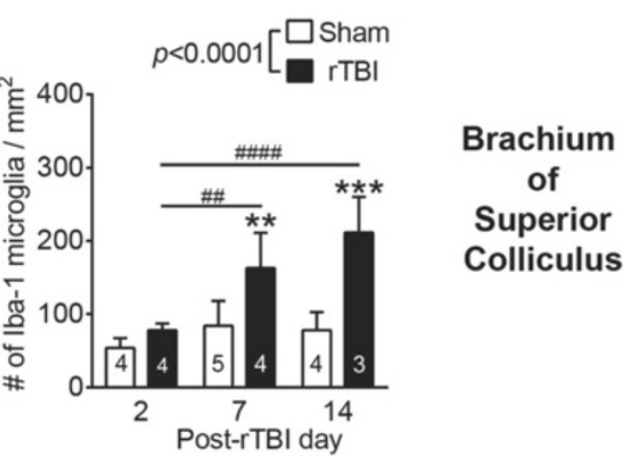

Figure 6 Quantitative analysis of microglial response to $\mathbf{r T B I}$. Bar graphs in the left column (A-D) indicate mean \pm SD fractal dimension for microglial morphology in (A) olfactory nerve layer, (B) corpus callosum, (C) brachium of superior colliculus, and (D) optic tract. Bar graphs in the right column (E-H) show mean \pm SD number of Iba-1 positive cells per $\mathrm{mm}^{2}$ in the same white matter regions. Data were analyzed by two-way ANOVA followed by a Tukey post-hoc test. Numbers inside the bars indicate sample size. For all graphs, ${ }^{*}$ indicates a significant rTBI effect within a particular time point while \# indicates a significant time effect within rTBl group. ${ }^{*}: p<0.05,{ }^{* *}: p<0.01,{ }^{* *}: p<0.001,{ }^{* * *}: p<0.0001$. \#\#: $p<0.01$, \#\#\#\#: $p<0.0001$.

render the "scaling" of rodent data to human to be an approximation at best. Nevertheless, under our experimental conditions, behavioral and neuropathological changes reliably occurred at lower scaled values of all kinematic parameters (except for impact duration) than those reported for NFL concussions [31,32]. Because clinical mTBI can occur under many different circumstances (e.g., falls, passengers and pedestrians in motor vehicle accidents, 
A

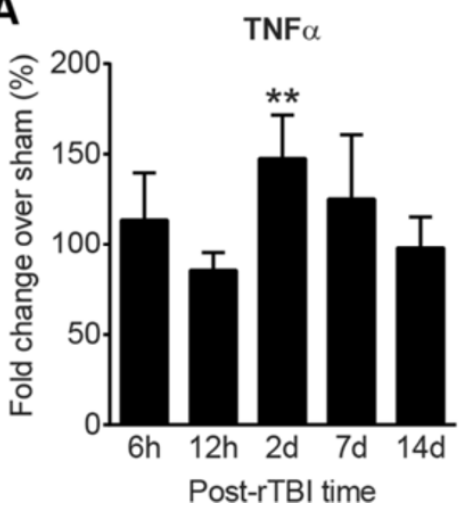

B

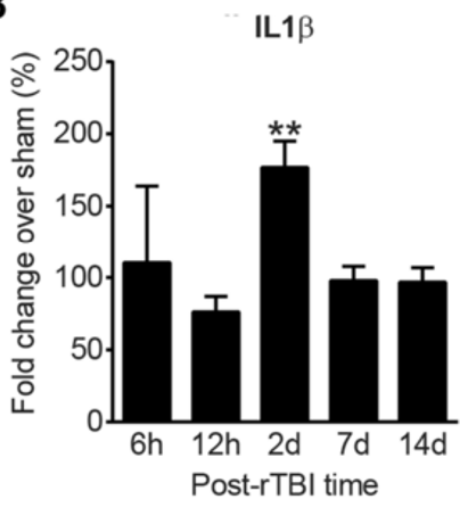

Figure 7 CHIMERA rTBI increases proinflammatory cytokine levels. Bar graphs represent mean \pm SD \% fold change in TNFa (A) and IL-1 $\beta$ (B) levels in rTBI brain lysates compared to the levels in the sham brain lysates at the respective time points. For both graphs, ${ }^{* *}$ indicates $p<0.01$ in comparison of rTBI vs sham, using multiple t-tests with Bonferroni corrections for multiple comparisons $(p=0.05 / 5=0.01)$.

non-NFL sports), an important area for future research will be to determine how various impact characteristics lead to functional and biochemical changes. The precision and flexibility CHIMERA offers with respect to impact parameters will help to refine the relationship between impact characteristics and physiological outcomes.

An additional advantage of CHIMERA is that it overcomes much of the variability observed with most $\mathrm{CHI}$ models. Typical weight-drop models $[29,33]$ have poor control over biomechanical input parameters, including friction and air resistance inside the guide tube that may contribute to variable outcomes. High incidence of skull fractures and limited dynamic range pose additional challenges in comparing results using weight-drop TBI models across different laboratories [24]. Head movement during many $\mathrm{CHI}$ impact models is often at least partially restricted by anchoring the head within a stereotaxic frame or by resting the animal on various types of support. In a recent modification, Kane et al. supported mice on a piece of aluminum foil that ruptures upon impact and leads to a $180^{\circ}$ rotation of the animal [34]. While this modification allows unrestricted head movement, it still includes possible sources of variability including stretching of the aluminum foil before yielding to the force generated by the weight-drop and less reliable and adjustable positioning of impact location compared to CHIMERA.

Loss of consciousness for $<30 \mathrm{~min}$ is one of the clinical criteria for mTBI [35] and the analogous measure in mice is LRR. In animal TBI models, an LRR of 15-30 min is considered moderate-severe TBI while an LRR of $<15 \mathrm{~min}$ is considered mild TBI [28]. The average LRR duration after CHIMERA-rTBI was $5.3 \mathrm{~min}$, indicating mild TBI. Interestingly, a second TBI occurring $24 \mathrm{~h}$ after the first impact did not prolong LRR time. Postconcussion patients may also show balance difficulties or postural instability up to several days [36-38], as well as mood changes such as irritability or anxiety [38,39].
Though general locomotor activities were not severely affected (Additional file 5: Figure S2), CHIMERA-rTBI resulted in deficits in fine motor coordination and neurological performance. Similar changes have also been reported by other groups [40,41]. CHIMERA-rTBI also increased thigmotaxis in TBI animals, suggesting an anxiety-like behavior [42]. Our model also revealed deficits in both working and spatial reference memory as assessed by the passive avoidance test and Barnes maze, respectively. Intriguingly, recovery of motor performance was faster than cognitive performance under the conditions of our study.

Diffuse axonal injury (DAI) is one of the characteristic pathologies of TBI $[30,43]$. Using silver staining, we observed increased argyrophilic fibers and punctate structures in several white matter tracts across the brain, suggesting a diffuse pattern of damaged axons. Axonal varicosities, a classical feature of DAI in humans, were also present [30]. Interestingly, both white matter areas that were close to (e.g., corpus callosum) and distant from (e.g., optic tract and olfactory nerve layer) the impact site were affected, suggesting that both coup and contrecoup injuries are present in our model. Affected white matter areas, including the corpus callosum, optic tract, and the olfactory system, have been reported in other $\mathrm{CHI}$ models that induce impact at the superior side of skull [44-47]. Several white matter areas showed increased argyrophilic staining as well as reactive microgliosis following rTBI, suggesting a possible relationship between axonal damage and neuroinflammation, in agreement with previous reports $[46,48,49]$. Interestingly, axonal injury in the optic tract continued to increase from 2 to $14 \mathrm{~d}$ suggesting that ongoing secondary injury processes overwhelmed endogenous repair mechanisms in the time frame examined in this study. Moreover, optic tract, a contrecoup injury site, showed the most intense silver uptake, which is in agreement with 


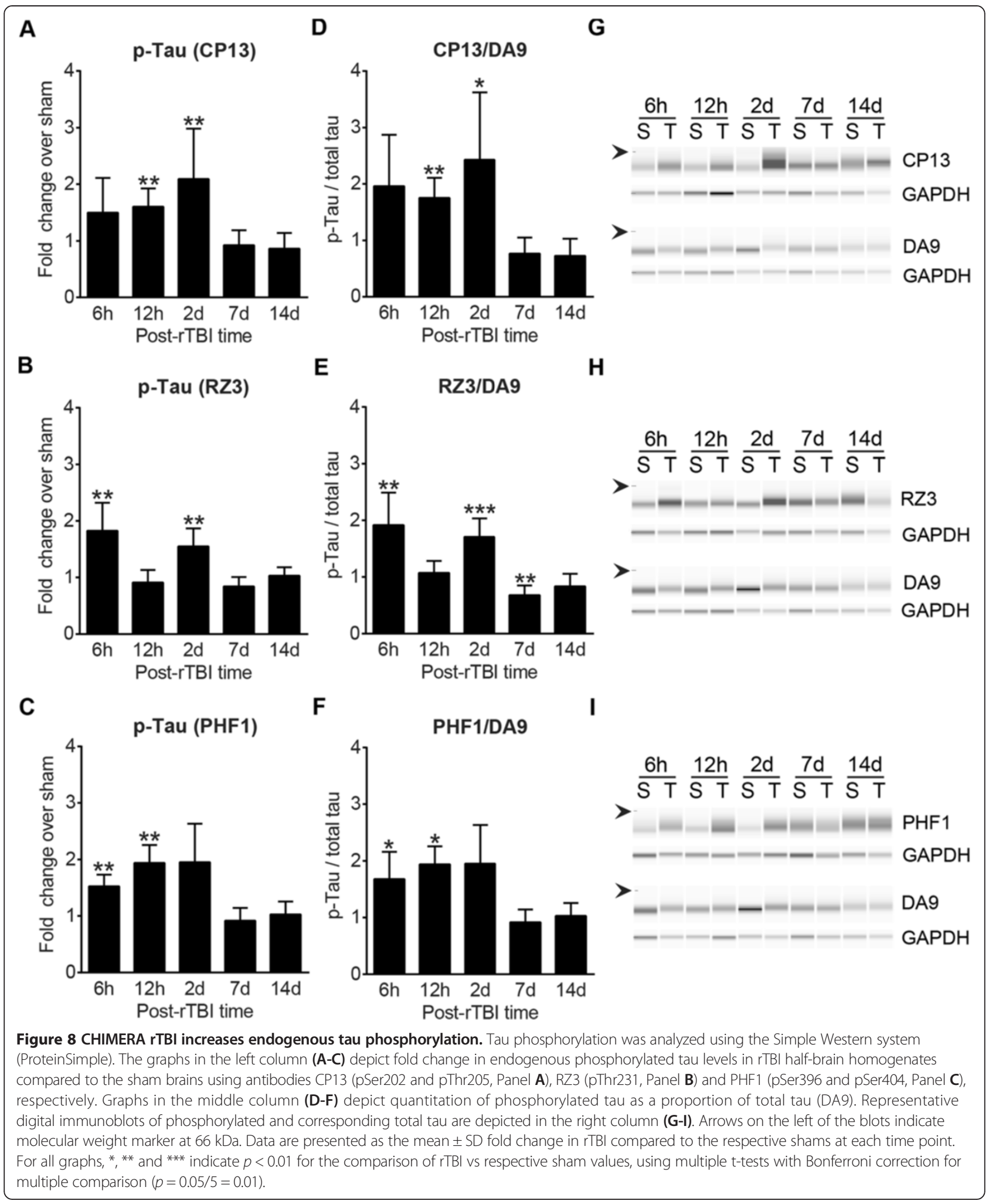

the common clinical observation that contrecoup injuries are more severe than the coup injuries [50]. On the other hand, axonal injury was resolved in the olfactory neuronal layer within $7 d$, suggesting efficient neural repair or active neuroregeneration in this region. Future studies will be designed to assess changes in cognitive functions and the 

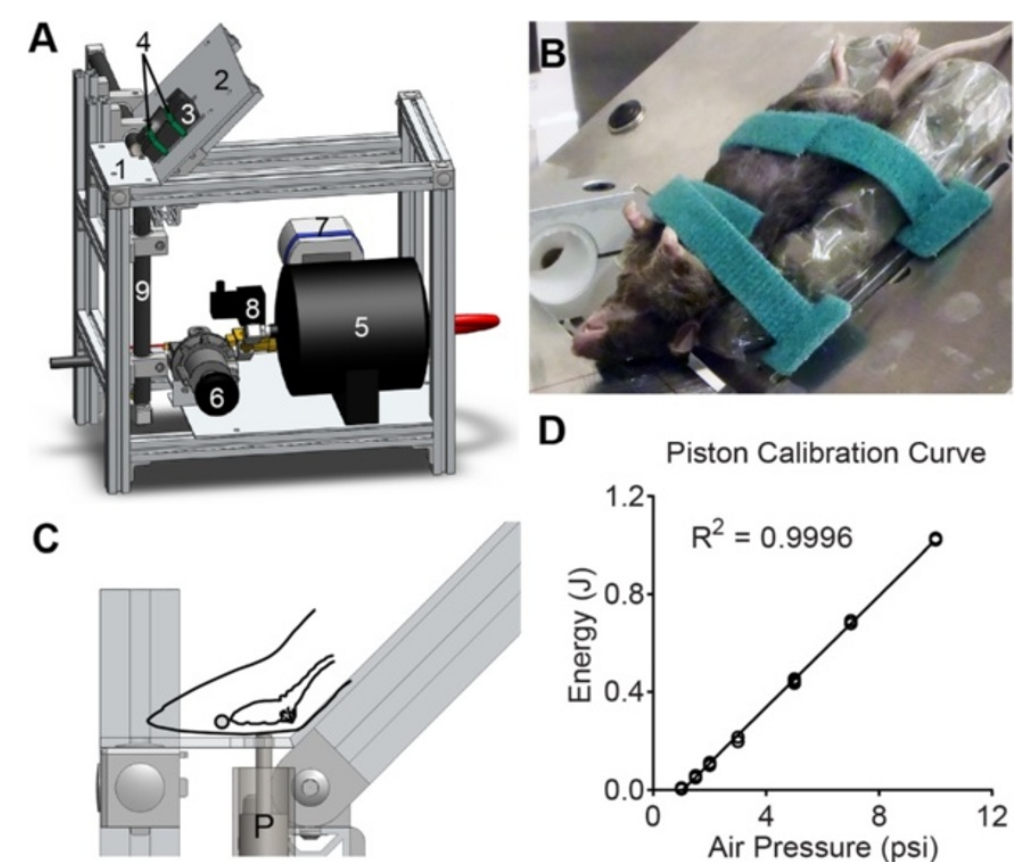

Figure 9 CHIMERA device and mouse head positioning. (A) The picture depicts the CHIMERA device. Various parts are labeled with numbers as follows: 1. head plate, 2. body plate, 3. animal bed, 4. Velcro straps, 5. air tank, 6. air pressure regulator, 7. digital pressure gauge, 8. two-way solenoid valve, 9 vertical piston barrel. (B) Close-up view of animal strapped on the holding platform. (C) Location of impact relative to the mouse head and brain. P: impact piston. (D) Air pressure-energy calibration curve was obtained by driving a $50 \mathrm{~g}$ piston at increasing air pressure values and calculating the resultant impact energy. The graph depicts three measurements for each air pressure value.

dynamics of axonal injury across several brain regions in our model over longer-term (up to 6 months) post-rTBI follow up.

Human and experimental TBI induce rapid neuroinflammatory responses as demonstrated by changes in cytokine levels (e.g., IL-1 $\beta$ and IL-6) and microglial activation [44,51-55]. Under our injury conditions, rTBI led to elevated IL-1 $\beta$ and TNF- $\alpha$ levels at $2 d$ after injury, which was accompanied by histological evidence of microgliosis. Because our animal ethics committee required the use of meloxicam for pre-emptive pain control, it is possible that an inflammatory response occurring during the first few hours after impact [52,54,55] was suppressed [56]. Iba-1-positive activated microglia were particularly evident along white matter tracts throughout the brain, whereas grey matter was essentially spared. Microglial activation as assessed by fractal analysis and cell density was significant at $2 \mathrm{~d}$ and persistent until $14 \mathrm{~d}$. However, as Iba-1 does not distinguish the source of immune cells, the increase in cell number in this study may be due to proliferation of resident immune cells in the brain or recruitment of immune cells from the periphery, or both.

Hyperphosphorylation of the cytoskeletal protein tau is a pathological event observed in many neurodegenerative diseases including Alzheimer's disease [48] and chronic traumatic encephalopathy [49]. In our model, we demonstrate that endogenous tau hyperphosphorylation is an early and dynamic event after rTBI in wild-type mice, again, in agreement with other models of CHI $[57,58]$. It should, however, be noted that post-TBI changes in phosphorylation of murine tau does not predict whether human tau will show similar dynamics. Further experiments using transgenic human tau mice will be required to investigate the influence of rTBI on tau deposition.

\section{Conclusions}

Here we report a novel, surgery-free $\mathrm{CHI}$ model that fully integrates biomechanical, functional, and neuropathological characteristics of TBI. CHIMERA allows precise control over mechanical inputs allowing reproducible head kinematics. Our study also shows that CHIMERATBI reliably replicates several key behavioral, biochemical, and neuropathological characteristics of human TBI including axonal injury, neuroinflammation, and functional deficits. Future studies will be conducted to characterize, in more detail, the relationships between kinematics and the resulting behavioral and neuropathological responses across a variety of impact parameters. The significant advantages CHIMERA offers over comparable rodent TBI models are expected to facilitate the acquisition of preclinical data with improved relevance to human TBI, thereby accelerating the pace of successful research to understand the mechanisms of 
TBI and to develop effective therapeutic approaches for this devastating condition.

\section{Methods \\ CHIMERA impactor}

The CHIMERA impactor consists of an aluminum frame that supports an animal holding platform above a pneumatic impactor system (Figure 9). The animal holding platform is composed of a fixed head plate that supports the animal's head in a supine position and a body plate that positions and secures the animal's torso. The head plate has a hole through which the tip of the impactor piston is projected to contact the animal's head. A cushion made from closed-cell foam surrounds the hole to minimize rebound impact when the animal's head falls back upon the head plate. Two perpendicular lines across the piston hole act as crosshairs for aligning the animal's head over the hole. The body plate holds a restraint system consisting of an animal bed of closed-cell foam contoured to the shape of the animal's body and two Velcro straps. The animal holding platform is attached to the frame by hinges and its angle of inclination can be adjusted. In this study, the angle was set to approximately $32^{\circ}$ such that the frontal and parietal bones lie flat over the hole in the head plate, thus delivering impact to the dorsal cortical region.

The pneumatic impactor system includes an accumulator air tank, pressure regulator, digital pressure gauge, two-way solenoid valve, and trigger button. The pressure regulator and digital pressure gauge allow precise adjustment of air pressure to $0.1 \mathrm{psi}(0.69 \mathrm{kPa})$, enabling accurate delivery of piston velocity and impact energy. Impact is induced with a $50 \mathrm{~g}$ free-floating chrome-coated steel piston whose trajectory is constrained to linear motion by a steel barrel. The piston barrel has an array of holes drilled near the muzzle end to vent air and equalize the pressure as the piston moves past them towards the impact site. The piston is accelerated by a controlled pulse of compressed air along the length of the barrel until it clears the venting holes.

The CHIMERA impactor was calibrated by measuring the exit velocity of the piston at various air pressures $(0.5,1,1.5,2,3,5,7$, and $10 \mathrm{psi})$ to determine the relationship between air pressure and piston velocity. Three measurements were taken at each pressure value. Each impact event was recorded by a high-speed video camera at 10,000 fps and tracked by video motion analysis software (TEMA Motion, Image Systems AB, Sweden). A 2nd order polynomial curve was used to fit the data. The $r^{2}$ value was 0.9996 (Figure 9D). Using this curve, the desired impact velocity or energy can be independently interpolated. By choosing the appropriate air pressure, impacts of input energy ranging from $0.01 \mathrm{~J}$ to $1 \mathrm{~J}$ can be precisely generated.

\section{CHIMERA TBI procedure}

All animal procedures were approved by the University of British Columbia Committee on Animal Care (protocol \# A11-0225) and were carried in strict accordance with the Canadian Council on Animal Care guidelines. Male C57Bl/6 mice (mean \pm SD body weight $33.9 \pm$ $4.6 \mathrm{~g})$ at 4 months of age were housed with a reversed $12 \mathrm{~h}$ light- $12 \mathrm{~h}$ dark cycle for at least 10 days before TBI. Animals were anaesthetized with isoflurane (induction: $4.5 \%$, maintenance: $2.5-3 \%)$ in oxygen $(0.9 \mathrm{~L} / \mathrm{min})$. Lubricating eye ointment was applied to prevent corneal drying. Meloxicam $(1 \mathrm{mg} / \mathrm{kg})$ and saline $(1 \mathrm{~mL} / 100 \mathrm{~g}$ body weight) were administered by subcutaneous injections for pain control and hydration, respectively. Animals were placed supine in the holding bed such that the top of the animal's head lay flat over a hole in the head plate, aligned using crosshairs such that the piston strikes the vertex of the head covering a $5 \mathrm{~mm}$ area surrounding the bregma (Figure 9B and $\mathrm{C}$ ). Impact was induced by pressing a trigger button that simultaneously fires the piston and when connected, activates a highspeed camera to record the resulting head trajectory. Isoflurane delivery was immediately stopped and the animal was continuously monitored until fully ambulatory. Total duration of isoflurane exposure was $\sim 4-8 \mathrm{~min}$. Twenty-four hours after the first impact, a second identical impact was delivered. Sham animals underwent all of these procedures, except for the impact. Approximately $3 \%$ of animals did not regain consciousness for $>$ $45 \mathrm{~min}$ or displayed severe motor dysfunction after TBI, and were thus euthanized.

\section{High-speed videography and kinematic analysis}

For kinematic analysis, an independent cohort of 8 mice was subjected to rTBI and impact events were recorded at 5,000 frames per second using a high-speed video camera (Q-PRI, AOS Technologies, Switzerland). Head motion was tracked using two markers, one being nontoxic paint applied on lateral side of head to mark the cheek area (Additional file 1: Figure S1, yellow arrow in the first image). Because the skin is loose over the bony skull, we also marked the position of the maxilla by wrapping dental floss positioned just caudal to the upper incisors around the animal's snout (Additional file 1: Figure S1, red arrow in the first image). Videos were analyzed using ProAnalyst motion analysis software (v 1.5.6.8, Xcitex Inc., Woburn, MA). The X and $Y$ coordinates of the position of each marker were tracked on a frame-by-frame basis and were processed with a $400-\mathrm{Hz}$ low-pass Butterworth filter to mitigate the noise in the recorded measurements. Velocities and accelerations were determined by discrete differentiation of the position data. Resultant linear velocity and acceleration were calculated as the magnitude of their 
respective $\mathrm{X}$ and $\mathrm{Y}$ components. Linear kinematic parameters were assessed from trajectories obtained by tracking the paint mark. Angular rotation of the head during TBI was determined by the angle of the line joining the dental floss and the paint mark with the horizon. After video capture, the dental floss was removed. Energy transferred from the piston to the head was determined using the equation $\mathrm{KE}=0.5 \times \mathrm{M}_{\mathrm{e}} \times$ $\Delta V^{2}$, where $M_{e}$ is the effective mass and is approximated by head mass $(3.4 \mathrm{~g})$ and $\Delta \mathrm{V}$ is a change in head velocity. A scaling factor $\lambda[\lambda=$ (mass of human brain/mass of mouse brain $)^{1 / 3}=13.8$ ] was used to estimate the human head-equivalent kinematic parameters from the animal data.

\section{Behavioral analyses}

LRR was calculated as the time interval from isoflurane discontinuation to the first sign of righting after each impact. Neurological impairment was assessed using the NSS [29] determined at $1 \mathrm{~h}$ and at 1,2 , and $7 \mathrm{~d}$ following the second TBI. NSS is a composite of ten different tasks that assess motor function, alertness, and physiological behavior (Additional file 4: Table S6). One point is awarded for the lack of a tested reflex or for the inability to perform the tasks, and no point for succeeding the task. A maximal NSS of 10 points thus indicates severe neurological dysfunction, with failure of all tasks. Motor performance was evaluated at 1, 2, 7, and $14 \mathrm{~d}$ after the second TBI using an accelerating rotarod as previously described [46]. Open field activity was assessed at 1, 7, and $14 \mathrm{~d}$ after the second TBI using a Plexiglas box $(14 " \times 24 " \times 14$ "). The floor of the box was virtually divided into 60 equal squares using an overhead digital camera and video tracking software (ANY-maze, v. 4.99, Stoelting Co, Wood Dale, IL). The field was further subdivided into a peripheral zone along the walls of the open field consisting of 28 squares that surrounded a central zone consisting of 32 squares. The animal was placed in the center of the box and spontaneous activity was recorded for $10 \mathrm{~min}$, including quantification of the total distance traveled and immobile time. The thigmotaxis index (TI) was calculated as: $\mathrm{TI}=\left(\mathrm{T}_{\mathrm{P}}-\mathrm{T}_{\mathrm{C}}\right) /\left(\mathrm{T}_{\mathrm{P}}+\mathrm{T}_{\mathrm{C}}\right)$ where $\mathrm{T}_{\mathrm{P}}$ and $\mathrm{T}_{\mathrm{C}}$ represent the time spent in the peripheral and central zones, respectively. Working and spatial reference memories were assessed from $7 \mathrm{~d}$ to $13 \mathrm{~d}$ after the second TBI using the passive avoidance task (7-10d) and the Barnes maze (8-13d), respectively. Passive avoidance testing was conducted in a device that consisted of two adjoining compartments, one illuminated $(20.3 \times 15.9 \times 21.3 \mathrm{~cm})$ and one darkened $(20.3 \times 15.9 \times 21.3 \mathrm{~cm})$, divided by a guillotine-style door (Med Associates Inc., St. Albans, VT). The floor of the compartments consisted of steel rods capable of delivering an electric foot-shock.
The electric shock was delivered by a programmable animal shocker (Med Associates Inc.). Each session consisted of placing mice into the illuminated compartment and using a timer to record the latency of the mice to cross into the darkened compartment. On 7d after the second TBI (training), mice received an electric foot-shock $(0.3 \mathrm{~mA}, 2 \mathrm{~s})$ as soon as they crossed from the illuminated into the darkened compartment. Following foot-shock, mice were removed from the apparatus and returned to their home cage. On $8 \mathrm{~d}$ to $10 \mathrm{~d}$ after the second TBI mice were tested for memory retention. The latency for the mice to cross into the darkened compartment was recorded. No shock was delivered during testing. Mice that did not cross over into the darkened compartment were allowed to remain in the illuminated compartment for the full $5 \mathrm{~min}$ and assigned a latency of $300 \mathrm{~s}$. Barnes maze testing was conducted on a grey circular platform (91 cm diameter) with 20 circular holes $(5 \mathrm{~cm}$ diameter; Stoelting Co) located in a $3.0 \times 3.6 \mathrm{~m}$ room. An escape box was positioned beneath one of the holes. Extra-maze visual cues consisted of black and white images (cross, lightning bolt, smiley face) printed on glossy white paper and placed on the walls surrounding the maze. Other visual cues included a cart with a laptop and the experimenter. A digital camera was placed $4 \mathrm{~m}$ above the center of the maze to record trials for the ANY-maze tracking system. For motivational purposes, mice were food restricted to $1 \mathrm{~g}$ of food per day from 8-13d after the second TBI and maintained at $90 \%$ of free feeding body weight. During testing, mice were exposed to aversive stimuli in the form of two lights $(100 \mathrm{~W})$ positioned at either side of the maze and a buzzer $(2.9 \mathrm{kHz}, 65 \mathrm{~dB})$ that hung $10 \mathrm{~cm}$ above the maze. On $8 \mathrm{~d}$ after the second TBI, mice completed one 5-min habituation trial to become familiar with the maze environment and to practice descending into the escape box. On 9d to 13d after the second TBI, mice were tested for memory retention. Mice were given four trials per day (15-min inter-trial interval) for five days. For each trial, mice were placed in a black plastic start tube ( $7 \mathrm{~cm}$ diameter, $12 \mathrm{~cm}$ height) on the center of the maze. After $10 \mathrm{~s}$, the start tube was raised and the buzzer was turned on to start the trial. Mice that were unable to locate the escape hole in $90 \mathrm{~s}$ were gently guided to it. Mice remained in the escape box for $10 \mathrm{~s}$ before being returned to their home cage.

\section{Tissue collection}

For histological analyses, mice were anesthetized with an intraperitoneal injection of $150 \mathrm{mg} / \mathrm{kg}$ ketamine (Zoetis) and $20 \mathrm{mg} / \mathrm{kg}$ xylazine (Bayer) at 2,7 , or $14 \mathrm{~d}$ after the second TBI, and brains were collected from perfused animals as described [46], except that $4 \%$ paraformaldehyde 
rather than neutral buffered formalin was used to post-fix hemisected brain tissue for histology. For biochemical analyses, brains were harvested as above at $6 \mathrm{~h}, 12 \mathrm{~h}, 2 \mathrm{~d}$, $7 \mathrm{~d}$, and $14 \mathrm{~d}$ post-rTBI, longitudinally hemisected and rapidly frozen over dry ice and stored at $-80^{\circ} \mathrm{C}$ until analysis.

\section{Microglial activation and silver staining}

Silver staining and Iba-1 histology was performed as described [46]. Microglial morphology was quantified using fractal analysis [59] using ImageJ (NIH). Three to four microglia were randomly chosen from 40Xmagnified Iba-1 stained images of olfactory nerve layer, corpus callosum, optic tract, and brachium of superior colliculus, converted to 8-bit images, and thresholded. Thresholded images were converted to outline images and analyzed using the FracLac plugin (Karperien, A., FracLac for ImageJ. http://rsb.info.nih.gov/ij/plugins/ fraclac/FLHelp/Introduction.htm. 1999-2013.). The box counting method was used and the mean fractal dimension was analyzed. The number of microglia in each white matter regions was quantified by scanning the entire area using a Olympus BX61 microscope at 10X magnification with a ProScan motorized XY stage (Prior Scientific Inc, Rockland, MA). The component images were stitched together into a montage using ImagePro Plus image analysis software (Media Cybernetics Inc., Rockville, MD). The number of Iba1-positive cells were manually counted in the entire white matter track region of interest (ROI). The area of ROI was measured by ImageJ as pixels and scaled to $\mathrm{mm}^{2}$. Cell density was finally expressed as number of Iba-1 positive cells per $\mathrm{mm}^{2}$. Silver staining intensity was quantified using ImageJ (version 1.48, NIH) on 40X-magnified images of olfactory nerve layer, corpus callosum, and optic tract. The images were thresholded and the ROI was manually selected. The ratio of area of positive signal in ROI to total ROI area was reported as percent positive.

\section{Biochemical analyses \\ Tissue processing}

For protein determination, half-brains were homogenized in RIPA lysis buffer as described [46].

\section{Cytokine ELISA}

Endogenous TNF $\alpha$ and IL-1 $\beta$ protein levels in the halfbrain homogenates were quantified by commercial ELISA kits (BD Biosciences OptEIA 559603 and 555268, respectively) following the manufacturer's instructions.

\section{Quantitative assessment of phosphorylated and total Tau by Simple Western analysis}

Phosphorylated and total tau were assessed using an automated capillary electrophoresis-sized-based [60,61] Simple Western system using the Wes machine (ProteinSimple, San Jose, CA). Simple Western is a gel-free, blot-free, capillary-based, automated protein immunodetection system that automates all the steps following sample preparation including sample loading, size-based protein separation, immunoprobing, washing, detection, and data analysis. All procedures were performed with manufacturer's reagents according to the user manual. Briefly, $5 \mu \mathrm{L}$ of RIPA lysate ( $2 \mu \mathrm{g}$ of protein) was mixed with $1.2 \mu \mathrm{L}$ of $5 \times$ fluorescent master mix and heated at $95^{\circ} \mathrm{C}$ for $5 \mathrm{~min}$. The samples, blocking reagent, wash buffer, primary antibodies, secondary antibodies, and chemiluminescent substrate were dispensed into designated wells in the manufacturer-provided microplate. Following plate loading, separation and immunodetection were performed automatically using default settings. Data were analyzed with Compass software (ProteinSimple). Samples were immunodetected using following monoclonal antibodies (all kind gifts from Dr. Peter Davies, Albert Einstein College of Medicine, Manhasset, NY, USA): RZ3 is directed against tau protein phosphorylated at Thr231 (1:25), PHF1 is directed against tau protein phosphorylated at Ser396 and Ser404 (1:25), CP13 is directed against tau protein phosphorylated at Ser202 and Thr404 (1:25), and DA9 is directed against phosphorylation-independent (total) tau (1:5000). GAPDH (clone 6C5, 1:5000, Chemicon) was used as a loading control. Levels of phosphorylated and total tau were normalized to GAPDH. Levels of phosphorylated tau were expressed as fold difference compared to sham controls at the respective time points.

The rTBI protocol and post-rTBI end points are summarized in Additional file 6: Figure S3.

\section{Statistical analyses}

The head kinematics data and graphs are presented as mean $\pm 95 \%$ CI. Behavioral data and graphs are presented as mean \pm SEM. All other data and graphs are presented as mean \pm SD unless otherwise specified. NSS, LRR, thigmotaxis, and rotarod data were analyzed using repeated measures two-way ANOVA followed by the Holm-Sidak posthoc test, as animals were tested repeatedly until sacrifice. Passive avoidance and Barnes maze data were analyzed by repeated measures two-way ANOVA. Iba-1 and silver staining data were analyzed by two-way ANOVA followed by Tukey's post-hoc test. For all the above statistical analyses, a $p$ value of $<0.05$ was considered significant. Tau phosphorylation and cytokine protein expression at each postrTBI time point was compared to the respective sham values by $t$ test followed by Bonferroni correction of multiple comparison, with $p$ value set to $<0.01$ (5 comparisons), for detecting statistical significance. Statistical analyses of behavioral data were performed using SigmaPlot (version 12.5, Systat Software Inc.). Statistical analyses for the rest of the data were performed using GraphPad Prism (version 6.04, GraphPad Software Inc). 


\section{Additional files}

Additional file 1: Figure S1. CHIMERA allows unrestricted head motion during TBI. Before impact, the mouse head was freely supported on a foam pad in the supine position. Velcro straps were applied to the torso. Impact from the piston deflects the head, which then subsequently returns to its original position on the foam pad. The images were taken at 5,000 fps, at an angle perpendicular to the direction of impact and along the mouse sagittal plane. Each image shown was 12 ms apart. Head movement was tracked using two markers: a dental floss (red arrow in the first image) wrapped around the maxilla and a non-toxic paint (yellow arrow in the first image) applied at the lateral size of the head.

Additional file 2: Movie S4. Mouse head motion following impact using CHIMERA. The impact event was recorded at 5,000 fps. The video shows movement of the mouse head following impact by the pneumatically-driven piston.

Additional file 3: Table S5. Comparison of kinematic parameters between rodent TBI models and human TBI [25,31,32,57,62-69].

Additional file 4: Table S6. Neurological severity score tasks [29]. Additional file 5: Figure S2. CHIMERA rTBI does not affect general mobility. General mobility was tested by the open field test at 1, 7 and 14d post-injury. No significant differences were observed between sham and $\mathrm{rTBI}$ mice in total distance travelled (A), number of lines crossed (B), or time spent immobile (C). Data are presented as the mean \pm SEM and analyzed by repeated measures two-way ANOVA followed by Holm-Sidak post-hoc test.

Additional file 6: Figure S3. Experimental Plan. The figure indicates the timeline for $\mathrm{rTBI} /$ sham procedure and behavioral, biochemical and histological end points at various post-rTBI time points used in this study. BM: Barnes maze, Iba-1: Iba-1 immunohistochemistry, NSS: neurological severity score, OF: open field behavior, PA: passive avoidance, RR: rotarod, SS: silver stain.

\section{Abbreviations}

CCl: Controlled-Cortical impact; CHI: Closed-Head injury; CHIMERA: Closed-Head Impact Model of Engineered Rotational Acceleration; DAl: Diffuse axonal injury; FP: Fluid percussion; LRR: Loss of righting reflex; mTBI: Mild traumatic brain injury; MVA: Motor vehicle accident; NFL: National football league; NSS: Neurological severity score; TBI: Traumatic brain injury; rTBI: Repeated traumatic brain injury.

\section{Competing interests}

The authors declare that they have no competing interests.

\section{Authors' contributions}

The CHIMERA device was conceived and designed by DRN, WC, PAC, and CLW and constructed and tested by KAM. DRN and WC carried out TBI procedures, collected head kinematics and behavioral data, performed histology and analyzed majority of the data. KMM carried out cognitive testing and analyzed cognitive testing data. MC provided technical support for TBI procedures and histology. Biochemistry samples were processed and tau immunoblotting was carried out by AW. Cytokine ELISA was carried out by JF. JR and AH provided support for histology. The manuscript was written by DRN, WC, and CLW and critically reviewed by PAC. All authors read and approved the manuscript.

\section{Acknowledgements}

This work was supported by an operating grant from the Canadian Institutes of Health Research to CLW (MOP 123461). DRN was supported by an Alzheimer Society Research Program (ASRP) Doctoral Award (Alzheimer Society of Canada, http://www.alzheimer.ca/en/Research/Alzheimer-SocietyResearch-Program). WHC is supported by an ASRP Doctoral Award and Comissao Technica de Atribuicao de Bolsas para Estudos Pos-Graduados Macao. The funders had no role in study design, data collection and analysis, decision to publish, or preparation of the manuscript. We are indebted to Dr. Peter Davies (Albert Einstein College of Medicine) for the kind gifts of tau antibodies.

\section{Author details}

${ }^{1}$ Department of Pathology and Laboratory Medicine, The University of British Columbia, Vancouver, BC, Canada. ${ }^{2}$ Graduate Program in Neuroscience, The University of British Columbia, Vancouver, BC, Canada. ${ }^{3}$ Departments of Mechanical Engineering and Orthopaedics, The University of British Columbia, Vancouver, BC, Canada. ${ }^{4}$ International Collaboration on Repair Discoveries, The University of British Columbia, Vancouver, BC, Canada. ${ }^{5}$ Djavad Mowafaghian Centre for Brain Health, The University of British Columbia, Vancouver, BC, Canada.

Received: 23 June 2014 Accepted: 20 November 2014 Published: 1 December 2014

\section{References}

1. Langlois JA, Rutland-Brown W, Wald MM: The epidemiology and impact of traumatic brain injury: a brief overview. J Head Trauma Rehabil 2006, 21:375-378.

2. Faul MM, Xu L, Wald MM, Coronado VG: Traumatic Brain Injury In The United States: Emergency Department Visits, Hospitalizations And Death 2002-2006. Atlanta: Centers for Disease Control and Prevention, National Center for Injury Prevention and Control; 2010.

3. Gerberding JL, Binder S: Report To Congress On Mild Traumatic Brain Injury In The United States: Steps To Prevent A Serious Public Health Problem. Atlanta: Centers for Disease Control and Prevention; 2003.

4. Cassidy JD, Carroll LJ, Peloso PM, Borg J, von Holst H, Holm L, Kraus J, Coronado VG: Incidence, risk factors and prevention of mild traumatic brain injury: results of the WHO Collaborating Centre Task Force on Mild Traumatic Brain Injury. J Rehabil Med 2004, Suppl. 43:28-60.

5. Tagliaferri F, Compagnone C, Korsic M, Servadei F, Kraus J: A systematic review of brain injury epidemiology in Europe. Acta Neurochir (Wien) 2006, 148:255-268.

6. Feigin VL, Theadom A, Barker-Collo S, Starkey NJ, McPherson K, Kahan M, Dowell A, Brown P, Parag V, Kydd R, Jones K, Jones A, Ameratunga S, BIONIC Study Group: Incidence of traumatic brain injury in New Zealand: a population-based study. Lancet Neurol 2013, 12:53-64.

7. Roozenbeek B, Maas Al, Menon DK: Changing patterns in the epidemiology of traumatic brain injury. Nat Rev Neurol 2013, 9:231-236.

8. Centers for Disease Control and Prevention: Nonfatal Traumatic Brain Injuries From Sports And Recreation Activities-United States, 2001-2005. MMWR Morb Mortal Wkly Rep 2007, 56:733-737.

9. Elder GA, Cristian A: Blast-related mild traumatic brain injury: mechanisms of injury and impact on clinical care. Mt Sinai J Med 2009, 76:111-118.

10. Hoge CW, McGurk D, Thomas JL, Cox AL, Engel CC, Castro CA: Mild traumatic brain injury in U.S. Soldiers returning from Iraq. N Engl J Med 2008, 358:453-463.

11. Taber KH, Warden DL, Hurley RA: Blast-related traumatic brain injury: what is known? J Neuropsychiatry Clin Neurosci 2006, 18:141-145.

12. Sevagan G, Zhu F, Jiang B, Yang KH: Numerical simulations of the occupant head response in an infantry vehicle under blunt impact and blast loading conditions. Proc Inst Mech Eng HJ Eng Med 2013, 227:778-787.

13. Rusnak M: Traumatic brain injury: giving voice to a silent epidemic. Nat Rev Neurol 2013, 9:186-187.

14. Jordan BD: The clinical spectrum of sport-related traumatic brain injury. Nat Rev Neurol 2013, 9:222-230.

15. Smith DH, Johnson VE, Stewart W: Chronic neuropathologies of single and repetitive TBI: substrates of dementia? Nat Rev Neurol 2013, 9:211-221.

16. Gavett BE, Stern RA, McKee AC: Chronic traumatic encephalopathy: a potential late effect of sport-related concussive and subconcussive head trauma. Clin Sports Med 2011, 30:179-188. xi.

17. Blumbergs PC: Pathology. In Head Injury - Pathophysiology and Management of Severe Closed Head Injury. Edited by Reilly P, Bullock R. London: Chapman and Hall; 1997:39-70.

18. Mclntosh TK, Smith DH, Meaney DF, Kotapka MJ, Gennarelli TA, Graham DI: Neuropathological sequelae of traumatic brain injury: relationship to neurochemical and biomechanical mechanisms. Lab Invest 1996, 74:315-342.

19. Davis AE: Mechanisms of traumatic brain injury: biomechanical, structural and cellular considerations. Crit Care Nurs Q 2000, 23:1-13.

20. Giza CC, Hovda DA: The neurometabolic cascade of concussion. J Ath/ Train 2001, 36:228-235. 
21. McAllister TW: Neurobiological consequences of traumatic brain injury. Dialogues Clin Neurosci 2011, 13:287-300.

22. Werner $C$, Engelhard K: Pathophysiology of traumatic brain injury. Br J Anaesth 2007, 99:4-9.

23. Graham DI, Mclntosh TK, Maxwell WL, Nicoll JA: Recent advances in neurotrauma. J Neuropathol Exp Neurol 2000, 59:641-651.

24. Namjoshi DR, Good C, Cheng WH, Panenka W, Richards D, Cripton PA, Wellington $\mathrm{CL}$ : Towards clinical management of traumatic brain injury: a review of models and mechanisms from a biomechanical perspective. Dis Model Mech 2013, 6:1325-1338.

25. Viano DC, Hamberger A, Bolouri H, Saljo A: Concussion in professional football: animal model of brain injury-part 15. Neurosurgery 2009, 64:1162-1173. Discussion 1173.

26. Gutierrez E, Huang Y, Haglid K, Bao F, Hansson HA, Hamberger A, Viano D: A new model for diffuse brain injury by rotational acceleration: I model, gross appearance, and astrocytosis. J Neurotrauma 2001, 18:247-257.

27. Holbourn AHS: Mechanics of head injuries. Lancet 1943, 242:438-441.

28. Dewitt DS, Perez-Polo R, Hulsebosch CE, Dash PK, Robertson CS: Challenges in the development of rodent models of mild traumatic brain injury. J Neurotrauma 2013, 30:688-701.

29. Flierl MA, Stahel PF, Beauchamp KM, Morgan SJ, Smith WR, Shohami E: Mouse closed head injury model induced by a weight-drop device. Nat Protoc 2009, 4:1328-1337.

30. Johnson VE, Stewart W, Smith DH: Axonal pathology in traumatic brain injury. Exp Neurol 2013, 246:35-43.

31. Pellman EJ, Viano DC, Tucker AM, Casson IR: Concussion in professional football: location and direction of helmet impacts-Part 2. Neurosurgery 2003, 53:1328-1340. Discussion 1340-1321.

32. Pellman EJ, Viano DC, Tucker AM, Casson IR, Waeckerle JF: Concussion in professional football: reconstruction of game impacts and injuries. Neurosurgery 2003, 53:799-812. Discussion 812-794.

33. Marmarou A, Foda MA, van den Brink W, Campbell J, Kita H, Demetriadou K: A new model of diffuse brain injury in rats. Part l: pathophysiology and biomechanics. J Neurosurg 1994, 80:291-300.

34. Kane MJ, Angoa-Perez M, Briggs DI, Viano DC, Kreipke CW, Kuhn DM: A mouse model of human repetitive mild traumatic brain injury. J Neurosci Methods 2012, 203:41-49.

35. Carroll LJ, Cassidy JD, Holm L, Kraus J, Coronado VG: Methodological issues and research recommendations for mild traumatic brain injury: the WHO Collaborating Centre Task Force on Mild Traumatic Brain Injury. J Rehabil Med 2004, Suppl 43:113-125.

36. Guskiewicz KM: Assessment of postural stability following sport-related concussion. Curr Sports Med Rep 2003, 2:24-30.

37. Putukian M: The acute symptoms of sport-related concussion: diagnosis and on-field management. Clin Sports Med 2011, 30:49-61.

38. Blume HK, Lucas S, Bell KR: Subacute concussion-related symptoms in youth. Phys Med Rehabil Clin N Am 2011, 22:665-681.

39. Daneshvar DH, Riley DO, Nowinski CJ, McKee AC, Stern RA, Cantu RC: Longterm consequences: effects on normal development profile after concussion. Phys Med Rehabil Clin N Am 2011, 22:683-700.

40. Mouzon B, Chaytow H, Crynen G, Bachmeier C, Stewart J, Mullan M, Stewart W, Crawford F: Repetitive mild traumatic brain injury in a mouse model produces learning and memory deficits accompanied by histological changes. J Neurotrauma 2012, 29:2761-2773.

41. Tsenter J, Beni-Adani L, Assaf Y, Alexandrovich AG, Trembovler V, Shohami E: Dynamic changes in the recovery after traumatic brain injury in mice: effect of injury severity on T2-weighted MRI abnormalities, and motor and cognitive functions. J Neurotrauma 2008, 25:324-333.

42. Simon P, Dupuis R, Costentin J: Thigmotaxis as an index of anxiety in mice. Influence of dopaminergic transmissions. Behav Brain Res 1994, 61:59-64.

43. Adams JH, Doyle D, Ford I, Gennarelli TA, Graham DI, McLellan DR: Diffuse axonal injury in head injury: definition, diagnosis and grading. Histopathology 1989, 15:49-59.

44. Shitaka Y, Tran HT, Bennet RE, Sanchez L, Levy MA, Dikranian K, Brody DL: Repetitive closed-skull traumatic brain injury in mice causes persistent multifocal axonal injury and microglial reactivity. J Neuropathol Exp Neurol 2011, 70:551-567.

45. Foda MA, Marmarou A: A new model of diffuse brain injury in rats. Part II: morphological characterization. J Neurosurg 1994, 80:301-313.

46. Namjoshi DR, Martin G, Donkin J, Wilkinson A, Stukas S, Fan J, Carr M, Tabarestani S, Wuerth K, Hancock RE, Wellington CL: The liver X receptor agonist GW3965 improves recovery from mild repetitive traumatic brain injury in mice partly through apolipoprotein E. PLoS One 2013, 8:e53529.

47. Creeley CE, Wozniak DF, Bayly PV, Olney JW, Lewis LM: Multiple episodes of mild traumatic brain injury result in impaired cognitive performance in mice. Acad Emerg Med 2004, 11:809-819.

48. Ballatore C, Lee VM, Trojanowski JQ: Tau-mediated neurodegeneration in Alzheimer's disease and related disorders. Nat Rev Neurosci 2007, 8:663-672

49. McKee AC, Stern RA, Nowinski CJ, Stein TD, Alvarez VE, Daneshvar DH, Lee HS, Wojtowicz SM, Hall G, Baugh CM, Riley DO, Kubilus CA, Cormier KA, Jacobs MA, Martin BR, Abraham CR, Ikezu T, Reichard RR, Wolozin BL, Budson AE, Goldstein LE, Kowall NW, Cantu RC: The spectrum of disease in chronic traumatic encephalopathy. Brain 2013, 136:43-64.

50. Drew LB, Drew WE: The contrecoup-coup phenomenon: a new understanding of the mechanism of closed head injury. Neurocrit Care 2004, 1:385-390.

51. Rooker S, Jander S, Van Reempts J, Stoll G, Jorens PG, Borgers M, Verlooy J: Spatiotemporal pattern of neuroinflammation after impact-acceleration closed head injury in the rat. Mediat Inflamm 2006, 2006:90123.

52. Taupin V, Toulmond S, Serrano A, Benavides J, Zavala F: Increase in IL-6, IL-1 and TNF levels in rat brain following traumatic lesion. Influence of pre- and post-traumatic treatment with Ro5 4864, a peripheral-type (p site) benzodiazepine ligand. J Neuroimmunol 1993, 42:177-185.

53. Perez-Polo JR, Rea HC, Johnson KM, Parsley MA, Unabia GC, Xu G, Infante SK, Dewitt DS, Hulsebosch CE: Inflammatory consequences in a rodent model of mild traumatic brain injury. J Neurotrauma 2013, 30:727-740.

54. Shein NA, Doron H, Horowitz M, Trembovler V, Alexandrovich AG, Shohami E: Altered cytokine expression and sustained hypothermia following traumatic brain injury in heat acclimated mice. Brain Res 2007, 1185:313-320.

55. Shohami E, Gallily R, Mechoulam R, Bass R, Ben-Hur T: Cytokine production in the brain following closed head injury: dexanabinol (HU-211) is a novel TNF-alpha inhibitor and an effective neuroprotectant. J Neuroimmunol 1997, 72:169-177.

56. Engelhardt G: Pharmacology of meloxicam, a new non-steroidal antiinflammatory drug with an improved safety profile through preferential inhibition of COX-2. Br J Rheumatol 1996, 35(Suppl 1):4-12

57. Goldstein LE, Fisher AM, Tagge CA, Zhang XL, Velisek L, Sullivan JA, Upreti C, Kracht JM, Ericsson M, Wojnarowicz MW, Goletiani CJ, Maglakelidze GM, Casey N, Moncaster JA, Minaeva O, Moir RD, Nowinski CJ, Stern RA, Cantu RC, Geiling J, Blusztajn JK, Wolozin BL, Ikezu T, Stein TD, Budson AE, Kowall NW, Chargin D, Sharon A, Saman S, Hall GF, et al: Chronic traumatic encephalopathy in blast-exposed military veterans and a blast neurotrauma mouse model. Sci Transl Med 2012, 4:143ra160.

58. Genis L, Chen Y, Shohami E, Michaelson DM: Tau hyperphosphorylation in apolipoprotein E-deficient and control mice after closed head injury. J Neurosci Res 2000, 60:559-564.

59. Karperien A, Ahammer $H$, Jelinek H: Quantitating the Subtleties of Microglial Morphology with Fractal Analysis. Front Cell Neurosci 2013, 7:1-18.

60. O'Neill RA, Bhamidipati A, Bi X, Deb-Basu D, Cahill L, Ferrante J, Gentalen E, Glazer M, Gossett J, Hacker K, Kirby C, Knittle J, Loder R, Mastroieni C, Maclaren M, Mills T, Nguyen U, Parker N, Rice A, Roach D, Suich D, Voehringer D, Voss K, Yang J, Yang T, Vander Horn PB: Isoelectric focusing technology quantifies protein signaling in 25 cells. Proc Natl Acad Sci 2006, 103:16153-16158.

61. Nguyen U, Squaglia N, Boge A, Fung PA: The Simple Western ${ }^{\mathrm{TM}}$ : a gel-free, blot-free, hands-free Western blotting reinvention. Nat Meth 2011, 8:v-vi.

62. Xiao-Sheng $H$, Sheng-Yu Y, Xiang Z, Zhou F, Jian-ning Z: Diffuse axonal injury due to lateral head rotation in a rat model. J Neurosurg 2000, 93:626-633.

63. Fijalkowski RJ, Stemper BD, Pintar FA, Yoganandan N, Crowe MJ, Gennarelli TA: New rat model for diffuse brain injury using coronal plane angular acceleration. J Neurotrauma 2007, 24:1387-1398.

64. Li XY, Li J, Feng DF, Gu L: Diffuse axonal injury induced by simultaneous moderate linear and angular head accelerations in rats. Neuroscience 2010, 169:357-369.

65. Wang HC, Duan ZX, Wu FF, Xie L, Zhang H, Ma YB: A new rat model for diffuse axonal injury using a combination of linear acceleration and angular acceleration. J Neurotrauma 2010, 27:707-719.

66. Davidsson J, Risling M: A new model to produce sagittal plane rotational induced diffuse axonal injuries. Front Neurol 2011, 2:41.

67. Li Y, Zhang L, Kallakuri S, Zhou R, Cavanaugh JM: Quantitative relationship between axonal injury and mechanical response in a rodent head impact acceleration model. J Neurotrauma 2011, 28:1767-1782. 
68. Viano DC, Casson IR, Pellman EJ, Bir CA, Zhang L, Sherman DC, Boitano MA: Concussion in professional football: comparison with boxing head impacts-part 10. Neurosurgery 2005, 57:1154-1172. Discussion 1154-1172.

69. Peng Y, Yang J, Deck C, Otte D, Willinger R: Development of head injury risk functions based on real-world accident reconstruction. Int $J$ Crashworthiness 2013, 19:105-114.

doi:10.1186/1750-1326-9-55

Cite this article as: Namjoshi et al:: Merging pathology with biomechanics using CHIMERA (Closed-Head Impact Model of Engineered Rotational Acceleration): a novel, surgery-free model of traumatic brain injury. Molecular Neurodegeneration 2014 9:55.

\section{Submit your next manuscript to BioMed Central and take full advantage of:}

- Convenient online submission

- Thorough peer review

- No space constraints or color figure charges

- Immediate publication on acceptance

- Inclusion in PubMed, CAS, Scopus and Google Scholar

- Research which is freely available for redistribution 